\title{
Collaborative Optimal Pricing Model of Dual-Channel Supply Chain
}

\author{
Zheng Liu ${ }^{1, *}$ and Qi Xu ${ }^{2}$ \\ ${ }^{I}$ School of Management, Shanghai University of Engineering Science, 201620, Shanghai, China; ${ }^{2}$ School of Glorious \\ Sun of Business and Management, Donghua University, 200051, Shanghai, China
}

\begin{abstract}
Dual-channel not only provides reasonable products but also a large quantity of opportunities, where the members' attitude towards risk has a major impact on channel optimization. In this paper, risks are classified as general risk and interruption risk. As for general risk, combined with risk-aversion attitude, mean-variance method is used to build optimal pricing model and expected utility model based on independent decision-making and collaborative decision-making mode. Besides, online channel substitution effect factor and ratio factor that manufacturer bears promotional cost for retailers are considered. For interruption risk, combined with risk-aversion attitude, optimal pricing model and expected utility model based on independent decision-making mode. Finally, through numerical analysis, it is proved that dualchannel collaborative pricing enables to avoid risks effectively, and the channel member with higher degree of risk aversion tends to take collaborative pricing strategy.
\end{abstract}

Keywords: Dual-channel supply chain, general risk, interruption risk, pricing decision, risk-aversion.

\section{INTRODUCTION}

With the development of information technology, manufacturers to adopt dual-channel supply chain pattern in order to respond to market demand in a timely manner, reduce out of stock or loss caused by unmatched supply and demand and improve the effectiveness of the supply chain. Dualchannel not only provides reasonable products but also a large quantity of opportunities. Therefore, how to make rational pricing strategies through effective cooperation has become one of significant issues in recent years. Meanwhile, an increasing number of researchers have started to pay more attention to this area.

Xiao Jian et al. assume that supply chain parties are risk neutral and makes a comparison analysis of how can reverse revenue sharing strategies efficiently coordinate channel conflicts [1]. Li et al. analyze the profit distribution mechanism in cooperation mode and shows that the optimal direct channel price and optimal retailer channel price are not influenced whether retailer and manufacturer cooperate or not, but influenced by risk aversion of two parties within certain conditions, manufacturer and retailer will achieve Pareto optimal if they choose cooperation [2]. Chernonog et al. seek to maximize each of three criteria: expected profit, the likelihood of achieving a profit target, and the profit for a given percentile [3]. Wang et al. find that the optimal prices of dual-channel, the added value and the expected profit decreased with the increasing risk-averse value and demand variance under decentralized decisions [4]. Huang et al. define the strategic robust supply chain design as the set of all Pareto-optimal configurations considering simultaneously the efficiency and the risk, where the risk is measured by the standard deviation of the efficiency [5]. Yoo consider the supplier's different risk attitudes, whether risk averse or risk neutral and indicate the optimal conditions for a generous return policy setting without quality enhancement [6]. Chen et al. observe that the agents' incentives will be perfectly aligned and independent of the risk attitudes, if the revenue sharing ratio equals the fixed cost sharing ratio [7]. Zhang et al. explore the issue of supply chain coordination by considering trade credit and its risk [8]. Zhu et al. investigate a risk-averse retailer within a newsvendor framework that is measured by conditional-value-at-risk $(\mathrm{CVaR})$, finding that coordinating revenue sharing contract and two-part tariff contract in the supply chain with risk neutral agents are still useful to coordinate the supply chain taking into account the degree of risk aversion of fashion retailer, whereas a more complex sales rebate and penalty (SRP) contract fails to do so [9].

Existing literature is rarely to classify risks, and how to choose decision-making mode as well as the impact of risk attitude on optimal pricing strategies are rarely deeply investigated. Based on dual-channel supply chain, in this paper, risks are classified as general risk and interruption risk, where general risk is able to be alleviated even avoided through channel cooperation, but interruption risk is hardly to deal with. For better discussion, for general risk, combined with risk-aversion attitude, mean-variance method is used to build optimal pricing model and expected utility model based on independent decision-making and collaborative decision-making mode. Besides, online channel substitution effect factor and ratio factor that manufacturer bears promotional cost for retailers are considered. For interruption risk, combined with risk-aversion attitude, optimal pricing model and expected utility model based on independent decision-making mode. Numerical simulations are conducted to explain collaborative decision-making can be able to re- 
spond to general risk and members of the higher degree of risk-aversion attitude tend to choose collaborative pricing strategy; as for interruption risk, it is difficult to avoid through coordination and the best decisions are taking independent pricing decisions.

\section{THE MODEL ASSUMPTIONS}

\subsection{Notations}

$E_{m}:$ Expected profit of manufacturer

$E_{r}:$ Expected profit of retailer

$E_{n}:$ Expected profit of the supply chain under independent pricing strategy

$E_{j}:$ Expected profit of the supply chain under collaborative pricing strategy

$E_{r L}:$ Expected utility of retailer

$E_{m L}:$ Expected utility of manufacturer

$E_{n L}$ : Expected utility of supply chain

$r_{i}$ : Unit shortage cost of online channel

$r_{r}$ : Unit shortage cost of retail channel

$s_{r}:$ Unit salvage of retail channel

$S_{i}$ : Unit salvage of online channel

$Q_{r}$ : Order quantity of retail channel

$x_{i}$ : Market demand for retail channel

$x_{r}$ : Market demand for online channel

$y$ : Overlap time $(y \leq 0$ indicates the manufacturer makes on time delivery; $y>0$ indicates the manufacturer delays $y$ cycles)

$t$ : Unit production cost of manufacturer

$w$ : Impact factor which is that the impact of lead time overlap on expected profit of two channels

$p_{i}:$ Unit price of online channel

$p_{r}:$ Unit price of retail channel

$c:$ Wholesale price offered by Manufacturer time

$h$ : Inventory holding cost of unit of product per unit

\section{$k$ : Promotional services cost offered by retailer}

\subsection{Basic Model}

In order to ensure a meaningful model constructed, this article has the following assumptions.
- In order to ensure smooth collaborative pricing, assuming that the expected profit of manufacturer and retailer $E_{m}, E_{r}$ are positive.

- Assuming that the market demand faced by online channel and retail channel are random variables.

- Assuming that time base for order cycle is $0, y \leq 0$ indicates the manufacturer makes delivery on time within the period; $y>0$ indicates the delay time when the manufacturer makes delayed delivery.

The major types of interruption are supply interruption and demand interruption. In this paper, it is assumed that supply interruption is mainly due to the inability of supplier to supply; while demand interruption is because orders are happen to decrease. The model discussed here is base model which mainly considers dual-channel supply chain members with risk neutral and risk aversion attitudes. Through introduction of substitution utility factor of online channel and promotional cost proportion factor that manufacturer undertakes for retailer, supply chain is able to achieve coordination.

Generally speaking, in a typical dual-channel supply chain system, market demand is distributed in both channels. Assuming the proportion of demand for online channel is $\theta$, so $(1-\theta)$ is for retail channel, in which $\theta \in(0,1)$; Proportion of increased market demand for retail channel and online channel are $\lambda$ and $(1-\lambda)$ respectively, of which $\lambda \in(0,1)$. With the rapid development of e-commerce, more and more customers choose online shopping so that online channel exerts great influence on retail channel. $b$ is substitution utility coefficient which represents how much online channel substitute retail channel, in which $b \in(0,1) ; a$ represents the total size of the market when there is only a single retail channel, $\bar{a}=a+\varepsilon, a>0$. Random variable $\mathcal{E}$ reflects market demand uncertainty, in which $\varepsilon \sim N\left(0, \sigma^{2}\right)$. In order to achieve the supply chain coordination, two channels tend to adopt collaborative mode. In this mode, manufacturer undertakes part of the retailer's promotional services so as to compensate the losses caused by the demand transfer due to the entry of online channel. $k$ denotes promotional services cost offered by retailer; $f \cdot k$ represents promotional cost that the manufacturer undertakes, in which $f$ is ratio, $f \in(0,1)$.

Based on Stackelberg Game Theory in supply chain management, manufacturer will announce wholesale price $c$, the ratio manufacturer undertakes promotional service $f$ and online price $p_{i}$; and next, retailer determines retail price as $p_{r}$, promotional services cost $k$ offered by retailer. The profit of manufacturer comprises the profit from online channel as well as the profit from retailer. The profit of manufacturer and retailer are hence as follows, respectively:

$$
\pi_{m}=\left(p_{i}-t\right) x_{i}+(c-t) x_{r}-f \cdot k
$$


$\pi_{r}=\left(p_{r}-c\right) x_{r}-(1-f) k$

Assuming wholesale price $c$ and the ratio $f$ as well as online price $p_{i}$ are known, backward induction is used to solve the second phase of the retailer's reaction function in the Stackelberg equilibrium. Therefore, we are able to draw decision schemes of retailer, manufacturer and supply chain as a whole.

\section{MODEL CONSTRUCTIONS WITHOUT CONSID- ERING RISK ATTITUDE}

In order to illustrate the effect of collaborative decisionmaking, optimal pricing models under independent and collaborative decision-making modes are established. To consider whether or not lead time overlaps, optimal profit models of independent and collaborative decision-making are further developed.

\subsection{Independent Pricing Model}

(1) Independent Pricing of Manufacturer

$$
\begin{aligned}
& \max \pi_{m}= \\
& \quad\left(p_{i}-t\right)\left\{(\theta+\lambda) \bar{a}-p_{i}-b\left[p_{i}-p_{r}\left(c, p_{i}, f\right)+\sqrt{k}\right]\right\} \\
& +(c-t)\left\{(1-\theta) \bar{a}-p_{r}\left(c, p_{i}, f\right)+b\left[p_{i}-p_{r}\left(c, p_{i}, f\right)+\sqrt{k}\right]\right\}-f \cdot k \\
& \text { s.t. } \quad x_{r}\left(p_{i}, p_{r}, \sqrt{k}\right) \geq 0 \\
& \quad \text { Due to } \frac{\partial^{2} \pi_{m}}{\partial p_{i}^{2}}=\frac{(1+b)(1-\theta) \bar{a}-(c-t)(1-\theta) \lambda b}{1+2 b}, \text { if } \\
& \quad(1+b) \bar{a}-(1-\theta) \lambda b<0, \text { namely } \frac{\partial^{2} \pi_{m}}{\partial p_{i}^{2}}<0 .
\end{aligned}
$$

The profit function $\pi_{m}$ is strictly concave in $p_{i}$, the optimal retail price $p_{i}$ uniquely exist. Let $\frac{\partial \pi_{m}}{\partial p_{i}}=0$, we can obtain: $p_{i}^{*}=\frac{(1+b)(\theta+\lambda) \bar{a}+b(1-\theta) \bar{a}+(1+2 b) t}{2(1+2 b)}$

(2) Independent Pricing of Retailer

$\max \pi_{r}=\left(p_{r}-c\right)\left[(1-\theta) \bar{a}-p_{r}+b\left(p_{i}-p_{r}+\sqrt{k}\right)\right]-(1-f) k$

s.t $\left\{\begin{array}{l}(\theta+\lambda) \bar{a}-p_{i}-b\left(p_{i}-p_{r}+\sqrt{a}\right) \geq 0 \\ k \geq 0\end{array}\right.$

By solving the first order derivative of $p_{r}$ in function $\pi_{r}$, we are able to obtain:

$$
p_{r}^{*}=\frac{2(1-f)\left[(1-\theta) \bar{a}+b p_{i}\right]+\left[2(1+b)(1-f)-b^{2}\right] c}{4(1+b)(1-f)-b^{2}}
$$

Due to $\frac{\partial^{2} \pi_{r}}{\partial p_{r}^{2}}=\frac{-[2(1-f)+b+(1+\theta)+\sqrt{k}]}{1+b}<0$, the profit function $\pi_{r}$ is strictly concave in $p_{r}$, the optimal retail price $p_{r}$ uniquely exist.

we obtain: $\sqrt{k}=\frac{b\left[(1-\theta) \bar{a}+b p_{i}\right]-b(1+b) c}{4(1+b)(1-f)-b^{2}}$

\subsection{Collaborative Pricing Model of Supply Chain}

$$
\begin{aligned}
& \max \pi_{s c}=\left(p_{i}-t\right)\left[(\theta+\lambda) \bar{a}-p_{i}-b\left(p_{i}-p_{r}+\sqrt{k}\right)\right]+ \\
& \qquad \begin{array}{l}
\left(p_{r}-t\right)\left[(1-\theta) \bar{a}-p_{r}+b\left(p_{i}-p_{r}+\sqrt{k}\right)\right]-k \\
x_{r}\left(p_{i}, p_{r}, \sqrt{k}\right) \geq 0 \\
x_{d}\left(p_{i}, p_{r}, \sqrt{k}\right) \geq 0
\end{array}
\end{aligned}
$$

Based on the constraints, we can find the solution as:

$$
\begin{aligned}
p_{i}^{*} & =\frac{(1+b)(1+\lambda) \bar{\alpha}+(1+2 b) t-(1-\theta) \bar{\alpha}}{2+4 b} \\
p_{r}^{*} & =\frac{(1+b)(1+\lambda) \bar{\alpha}+(1+2 b) t-(\theta+\lambda) \bar{\alpha}}{2+4 b} \\
& \frac{\partial^{2} \pi_{s c}}{\partial p_{i}^{2}} \cdot \frac{\partial^{2} \pi_{s c}}{\partial p_{r}^{2}}-\frac{\partial^{2} \pi_{s c}^{2}}{\partial p_{i} \partial p_{r}}=\frac{(1-\lambda)(b+\bar{a})+(1-\theta) t+2 b}{1+4 b}>0
\end{aligned}
$$

and $\frac{\partial^{2} \pi_{s c}}{\partial p_{i}^{2}}=\frac{(1-\lambda) b+\theta \bar{a}+t}{1+4 b}>0$, we can find maximum of $\pi_{s c}$ in the interval.

If $\theta+\lambda \geq 1-\theta$, we have $p_{r}^{*}<p_{i}^{*}$; namely when sales volume of online channel is smaller than that of retail channel, retail price is lower than online price.

If $\theta+\lambda<1-\theta$, we have $p_{r}^{*}>p_{i}^{*}$; namely when sales volume of online channel is larger than that of retail channel, retail price is higher than online price.

\subsection{Expected Profit Models under Independent Decision- Making}

(1) Expected Profit of Retailer

When the lead time of the two channels is not overlapped and manufacturers enable to supply on time without risk, revenue expressions are as follows based on retail order quantity is greater or smaller than market demand:

$$
\begin{aligned}
& \int_{0}^{Q_{r}}\left[\left(p_{r}-c\right) x_{r}-\left(c-s_{r}\right)\left(Q_{r}-x_{r}\right)\right] f\left(x_{r} \mid y, y \leq 0\right) d x_{r} \\
& \int_{Q_{r}}^{\infty}\left[\left(p_{r}-c\right) x_{r}-r_{r}\left(x_{r}-Q_{r}\right)\right] f\left(x_{r} \mid y, y \leq 0\right) d x_{r}
\end{aligned}
$$

According to the above two equations, we can conclude expected profit of retailer when the lead time of the two channels is not overlapped, so there does not exist supply risk: 


$$
\begin{aligned}
& E_{r}\left(Q_{r} \mid y, y \leq 0\right)= \\
& \int_{0}^{Q_{r}}\left[\left(p_{r}-c\right) x_{r}-\left(c-s_{r}\right)\left(Q_{r}-x_{r}\right)\right] f\left(x_{r} \mid y, y \leq 0\right) d x+ \\
& \int_{Q_{r}}^{\infty}\left[\left(p_{r}-c\right) Q_{r}-r_{r}\left(x_{r}-Q_{r}\right)\right] f\left(x_{r} \mid y, y \leq 0\right) d x_{r}
\end{aligned}
$$

when the lead time of the two channels is not overlapped, due to limitations in the production capacity of the manufacturer, delivery extension may arise which will bring supply risks so that affect retail sales. Assuming that $w$ is impact factor which represents the impact of lead time overlap on expected profit, so expected profit of retailer in this case can be expressed as:

$$
\begin{aligned}
& E_{r}\left(Q_{r} \mid y, y>0\right)= \\
& w\left[\int_{0}^{Q_{r}}\left[\left(p_{r}-c\right) x_{r}-\left(c-s_{r}\right)\left(Q_{r}-x_{r}\right)\right] f\left(x_{r} \mid y, y \geq 0\right) d x+\right. \\
& \quad \int_{Q_{r}}^{\infty}\left[\left(p_{r}-c\right) Q_{r}-r_{r}\left(x_{r}-Q_{r}\right)\right] f\left(x_{r} \mid y, y \geq 0\right) d x_{r}
\end{aligned}
$$

Where $p_{r}$ equals to $p_{r}^{*}$ in Equation (6).

Based on the above two cases, retailer's overall expected return can be expressed as:

$E_{r}=E_{r}\left(Q_{r} \mid y, y \leq 0\right)+E_{r}\left(Q_{r} \mid y, y>0\right)$

\section{(2) Expected Profit of Manufacturer}

When lead time is not overlapped, namely $y \leq 0$, the expected profit of manufacturer is as follows:

$$
M(y \mid y \leq 0)=(c-t+h \times y) Q_{r}+\left(p_{i}-t\right) \int_{-\infty}^{+\infty} x_{i} d x_{i}
$$

when the manufacturer makes on time delivery, namely $y=0$, no additional costs incur. However, when the supply time of manufacturer is earlier than lead time which is required by online store, inventory cost arise in the period of time in advance lead time must be borne by online store. Inventory cost is related with overlap time $y$, inventory holding cost $h$ and order quantity $Q_{r}$.

When lead time is overlapped, namely $y>0$, the expected profit of manufacturer is as follows:

$$
M(y \mid y>0)=w(c-t) Q_{r}+w\left(p_{i}-t\right) \int_{-\infty}^{+\infty} x_{i} d x_{i}
$$

Based on the above two Equations (16) and (17), we can obtain the expected profit of manufacturer:

$$
\begin{aligned}
E_{m}= & \int_{0}^{\infty}\left[(c-t+h y) Q_{r}+\left(p_{i}-t\right) \int_{-\infty}^{+\infty} x_{i} d x_{i}\right] g(y) d y+ \\
& \int_{-\infty}^{0}\left[w(c-t) Q_{r}+w\left(p_{i}-t\right) \int_{-\infty}^{+\infty} x_{i} d x_{i}\right] g(y) d y
\end{aligned}
$$

where $p_{i}$ equals to $p_{i}^{*}$ in Equation (4).

\section{(3) Expected Profit of Supply Chain}

Expected profit of the supply chain is made up of the profit of retail channel and online channel, which equals the profit of manufacturer and retailer, minus the revenue obtained from the manufacturer wholesale to retailer, namely:

$$
\begin{aligned}
& E_{n}=E_{r}+E_{m}-\int_{0}^{\infty}(c-t+h y) Q_{r} g(y) d y+ \\
& \int_{-\infty}^{0} w(c-t) Q_{r} g(y) d y
\end{aligned}
$$

\subsection{Expected Profit Models under Collaborative Deci- sion-Making}

When motivational strategies are used for collaboration among channels, both sides are able to make use of each other's pre-sale information to predict demand of its own channel, to better avoid risks caused by uncertainty. Meanwhile, due to the sharing of information between the two channels, manufacturers can minimize the risk of overlap of lead time. To maximize the overall benefits of supply chain as a whole, expected profit of supply chain under collaborative decision-making is shown in Equation (20), where $p_{i}$ and $p_{r}$ equals $p_{i}^{*}$ in Equation (9) and $p_{r}^{*}$ in Equation (10).

$$
\begin{array}{r}
E_{j}=\left(p_{i}-t\right)(\theta+\lambda)\left[a-p_{i}-b\left(p_{i}-p_{r}+\sqrt{k}\right)\right]+ \\
\left(p_{r}-t\right)(1-\theta)\left[a-p_{r}-b\left(p_{i}-p_{r}+\sqrt{k}\right)\right]
\end{array}
$$

\section{MODEL CONSTRUCTION UNDER GENERAL RISK CONSIDERING RISK-AVERSION ATTITUDE}

\subsection{Independent Decision-Making Model}

To consider the lack of information sharing when both sides adopt independent decision-making strategies, pricing decisions made by manufacturer and retailer are affected by their attitudes towards risk. In order to better analyze how much decision-makers would like to escape risk, we use the mean-variance to measure their expected utility, namely $U=E-r k \cdot \sqrt{\operatorname{Var}}, r k \in(0,1)$.

\section{(1) Expected Utility of Retailer} tailer:

In this case, its expectation and variance of profit of re-

$$
\begin{aligned}
& E_{r}=(1-\lambda)\left\{E_{r}\left(Q_{r} \mid y, y \leq 0\right) \cdot \int_{-\infty}^{0} g(y) d y+E_{r}\left(Q_{r} \mid y, y \geq 0\right)\right. \\
& \left.\cdot \int_{0}^{\infty} g(y) d y\right\} \\
& \operatorname{Var}\left(E_{r}\right)=\sigma^{2}\left[\left(p_{r}-c\right)(\theta+\lambda)\right]^{2}\left[\int_{-\infty}^{0} g(y) d y+w \int_{0}^{\infty} g(y) d y\right]^{2}
\end{aligned}
$$
tailer:

Then, the objective function of expected utility of re- 


$$
\begin{aligned}
& U\left(E_{r}\right)=(1-\lambda)\{[[ \\
& \left.\int_{0}^{Q_{r}}\left(p_{r}-c\right) x_{r}-\left(c-S_{r}\right)\left(Q_{r}-x_{r}\right)\right] f\left(x_{r} \mid y, y \leq 0\right) d x_{r}+ \\
& \left.\int_{Q_{r}}^{\infty}\left[\left(p_{r}-c\right) Q_{r}-r_{r}\left(x_{r}-Q_{r}\right)\right] \cdot f\left(x_{r} \mid y, y \leq 0\right) d x_{r}\right] . \\
& \left(\int_{-\infty}^{0} g(y) d y\right)+w \int_{0}^{Q_{r}}\left[\left(p_{r}-c\right) x_{r}-\right. \\
& \left.\left(c-s_{r}\right)\left(Q_{r}-x_{r}\right)\right] f\left(x_{r} \mid y, y \geq 0\right) d x_{r}+ \\
& \int_{Q_{r}}^{\infty}\left[\left(p_{r}-c\right) Q_{r}-r_{r}\left(x_{r}-Q_{r}\right)\right] f\left(x_{r} \mid y, y \geq 0\right) d x_{r} \cdot \int_{0}^{\infty} g(y) d y- \\
& \left.\sigma r k_{r} \cdot\left[\left(p_{r}-c\right)(\theta+\lambda)\right]\left[\int_{-\infty}^{0} g(y) d y+w \int_{0}^{\infty} g(y) d y\right]\right\}
\end{aligned}
$$

(2) Expected Utility of Manufacturer

According to above analysis, similarly, the objective function of manufacturer is:

$$
\begin{aligned}
U\left(E_{m}\right)= & \int_{0}^{\infty}\left[\left(c-t+h_{y}\right) Q_{r}+\left(p_{i}-t\right) \int_{-\infty}^{+\infty} x_{i} d x_{i}\right] g(y) d y+ \\
& \int_{-\infty}^{0}\left[w(c-t) Q_{r}+\right. \\
& \left.w\left(p_{i}-t\right) \int_{-\infty}^{+\infty} x_{i} d x_{i}\right] g(y) d y-\sigma r k_{i} \cdot \\
& {\left[\left(p_{i}-t\right)(\theta+\lambda)+(c-t)(1-\theta)\right] \int_{-\infty}^{0} g(y) d y }
\end{aligned}
$$

where $r k_{r}, r k_{i}$ denote attitudes of manufacturer and retailer towards risks, respectively. $r k=0$ denotes risk-neutral attitude; $r k<0$ represents risk appetite attitude; $r k>0$ denotes risk-aversion attitude; the greater $r k$ is, decision makers are more unwilling to face the impact brought by risk.

The manufacturer firstly proposes online price and wholesale price, and then retailer determines retail price, which belongs to master-slave Stackelberg game. In the first stage, reverse recursion is used to find optimal pricing strategies of manufacturer and retailer under risk-averse attitude:

$$
\begin{aligned}
p_{i}^{*}= & \frac{t}{2}+\frac{a-\sigma \cdot r k_{i}}{2(1+2 b)}\left[\int_{-\infty}^{0} g(y) d y+w \int_{0}^{\infty} g(y) d y\right] \\
p_{r}^{*}= & c+4 b(1+b) c+a(3-3 \theta+2 b(3+b-2 \theta+\lambda+b \lambda))- \\
& 2(1+b)(1+b-\theta+b \lambda) \cdot \sigma \cdot r k_{i} \cdot \\
& \int_{-\infty}^{0} g(y)-\frac{(1+2 b)(1-\theta) \int_{0}^{\infty} g(y) d y}{4(1+2 b)(1+b)}
\end{aligned}
$$

(3) Expected Utility of Supply Chain

Similarly, we can obtain expected utility of supply chain:

$$
\begin{aligned}
E_{n}= & U\left(E_{r}\right)+U\left(E_{m}\right)-\int_{0}^{\infty}\left(c-t+h_{y}\right) Q_{r} g(y) d y- \\
& \int_{-\infty}^{0} w(c-t) Q_{r} g(y) d y
\end{aligned}
$$

\subsection{Collaborative Decision-Making Model}

When the two channels hold risk-aversion attitude, both sides tend to take collaborative strategy to avoid risks. Simi- larly, due to information sharing among the two channels, manufacturer can minimize the risk caused by lead time overlap as much as possible. The expected profit.

\section{MODEL CONSTRUCTION UNDER INTERRUPTION RISK CONSIDERING RISK-AVERSION ATTITUDE}

The above discussion mainly considers how the two channels work under the general risks of the supply chain.

However, the risk does not always occur gradually, sometimes it is difficult to predict the risk when in emergencies. From a management practice, when extreme risks like interruption happen, the two channels tend to take independent decisions; meanwhile channels with different risk attitudes will take different actions.

$$
\begin{aligned}
E_{j}= & \left(p_{i}-t\right)(\theta+\lambda)\left[a-p_{i}-b\left(p_{i}-p_{r}+\sqrt{k}\right)\right]+ \\
& \left(p_{r}-t\right)(1-\theta)\left[a-p_{r}-b\left(p_{i}-p_{r}+\sqrt{k}\right)\right]- \\
& \sigma r k_{r} \cdot\left[\left(p_{r}-c\right)(\theta+\lambda)\right][ \\
& \left.\int_{-\infty}^{0} g(y) d y+w \int_{0}^{\infty} g(y) d y\right] r k_{i} \cdot\left[\left(p_{i}-t\right)(\theta+\lambda)+\right. \\
& (c-t)(1-\theta)] \int_{-\infty}^{0} g(y) d y
\end{aligned}
$$

\subsection{Supply Interruption Risk}

(1) Expected Utility of Retailer under Independent Decision-making

$$
\begin{aligned}
& U_{L}\left(E_{r_{L}}\right) \\
& =(1-\lambda)\left\{\int_{0}^{\infty}\left[\left(-r_{r} \cdot x_{r}\right) f\left(x_{r} \mid y, y \leq 0\right) d x_{r}\right] \cdot\left(\int_{-\infty}^{0} g(y) d y\right)+\right. \\
& \int_{0}^{\infty}\left[\left(-r_{r} \cdot x_{r}\right) f\left(x_{r} \mid y, y \geq 0\right) d x_{r} \cdot \int_{0}^{\infty} g(y) d y-\right. \\
& \left.\sigma \cdot r k_{r} \cdot\left[\left(p_{r}-c\right)(\theta+\lambda)\right]\left[\int_{-\infty}^{0} g(y) d y+w \int_{0}^{\infty} g(y) d y\right]\right\}
\end{aligned}
$$

(2) Expected Utility of Manufacturer under Independent Decision-making

$$
\begin{aligned}
& U_{L}\left(E_{m L}\right) \\
& =\int_{-\infty}^{0}\left[w\left(p_{i}-t\right) \int_{-\infty}^{+\infty} x d x_{i}\right] \cdot g(y) d y-\sigma r k_{r} \cdot\left[\left(p_{i}-t\right)(\theta+\lambda)+\right. \\
& (c-t)(1-\theta)] \int_{-\infty}^{0} g(y) d y
\end{aligned}
$$

where $p_{i}$ and $p_{r}$ equals $p_{i}^{*}$ in Equation (9) and $p_{r}^{*}$ in Equation (10).

(3) Expected Utility of Supply Chain

$$
E_{n L}=U\left(E_{r L}\right)+U_{L}\left(E_{m L}\right)
$$

\subsection{Supply Interruption Risk}

(1) Expected Utility of Retailer under Independent Decision-making of dual-channel supply chain system under collaborative can be obtained, shown in Equation (28), 


$$
\begin{aligned}
& U_{L}\left(E_{r L}\right) \\
& =(1-\lambda)\left\{\left[\left[\int_{0}^{Q_{r}}\left(p_{r}-c\right) \cdot 0-Q_{r}\left(c-s_{r}\right)\right] f(0 \mid y, y \leq 0) d x_{r}+\right.\right. \\
& \left.\quad \int_{Q_{r}}^{\infty}\left[\left(p_{r}-c\right) Q_{r}+r_{r} \cdot Q_{r}\right] f(0 \mid y, y \leq 0) d x_{r}\right] \cdot\left(\int_{-\infty}^{0} g(y) d y\right)+ \\
& \quad w \int_{0}^{Q_{r}}\left(s_{r}-c\right) \cdot Q_{r} f(0 \mid y, y \geq 0) d x_{r}+\int_{Q_{r}}^{\infty}\left[\left(p_{r}-c\right) \cdot Q_{r}+r_{r} .\right. \\
& \left.Q_{r}\right] f\left(x_{r} \mid y, y \geq 0\right) d x_{r} \cdot \int_{0}^{\infty} g(y) d y- \\
& \quad \sigma r k_{r} \cdot\left[\left(p_{r}-c\right)(\theta+\lambda)\left[\int_{-\infty}^{0} g(y) d y+w \int_{0}^{\infty} g(y) d y\right]\right\}
\end{aligned}
$$

(2) Expected Utility of Manufacturer under Independent Decision-making

$$
\begin{aligned}
U_{L}\left(E_{m L}\right)= & \int_{0}^{\infty}\left[\left(c-t+h_{y}\right) Q_{r} \cdot g(y) d y+\right. \\
& \int_{-\infty}^{0} w(c-t) Q_{r} \cdot g(y) d y-\sigma \cdot r k_{i} \cdot\left[\left(p_{i}-t\right)(\theta+\lambda)+\right. \\
& (c-t)(1-\theta)] \int_{-\infty}^{0} g(y) d y
\end{aligned}
$$

(3) Expected Utility of Supply Chain

\subsection{Supply Interruption Risk}

(1) Expected Utility of Retailer under Independent Decision-making

$$
\begin{aligned}
U_{L}\left(E_{r_{L}}\right)= & (1-\lambda) \\
& \left\{\int_{0}^{\infty}\left[\left(-r_{r} \cdot x_{r}\right) f\left(x_{r} \mid y, y \leq 0\right) d x_{r}\right] \cdot\left(\int_{-\infty}^{0} g(y) d y\right)+\right. \\
& \int_{0}^{\infty}\left[\left(-r_{r} \cdot x_{r}\right) f\left(x_{r} \mid y, y \geq 0\right) d x_{r} \cdot \int_{0}^{\infty} g(y) d y-\right. \\
& \left.\sigma \cdot r k_{r} \cdot\left[\left(p_{r}-c\right)(\theta+\lambda)\right]\left[\int_{-\infty}^{0} g(y) d y+w \int_{0}^{\infty} g(y) d y\right]\right\}
\end{aligned}
$$

(2) Expected Utility of Manufacturer under Independent Decision-making

$$
\begin{aligned}
& U_{L}\left(E_{m L}\right)= \\
& \int_{-\infty}^{0}\left[w\left(p_{i}-t\right) \int_{-\infty}^{+\infty} x d x_{i}\right] \cdot g(y) d y-\sigma r k_{r} \cdot\left[\left(p_{i}-t\right)(\theta+\lambda)+\right. \\
& (c-t)(1-\theta)] \int_{-\infty}^{0} g(y) d y
\end{aligned}
$$

where $p_{i}$ and $p_{r}$ equals $p_{i}^{*}$ in Equation (9) and $p_{r}^{*}$ in Equation (10).

(3) Expected Utility of Supply Chain

$$
E_{n L}=U\left(E_{r L}\right)+U_{L}\left(E_{m L}\right)
$$

\subsection{Demand Interruption Risk}

(1) Expected Utility of Retailer under Independent Decision-making

$$
\begin{aligned}
& U_{L}\left(E_{r L}\right) \\
& =(1-\lambda)\left\{\left[\left[\int_{0}^{Q_{r}}\left(p_{r}-c\right) \cdot 0-Q_{r}\left(c-s_{r}\right)\right] f(0 \mid y, y \leq 0) d x_{r}+\right.\right. \\
& \left.\int_{Q_{r}}^{\infty}\left[\left(p_{r}-c\right) Q_{r}+r_{r} \cdot Q_{r}\right] f(0 \mid y, y \leq 0) d x_{r}\right] \cdot\left(\int_{-\infty}^{0} g(y) d y\right)+ \\
& \quad w \int_{0}^{Q_{r}}\left(s_{r}-c\right) \cdot Q_{r} f(0 \mid y, y \geq 0) d x_{r}+\int_{Q_{r}}^{\infty}\left[\left(p_{r}-c\right) \cdot Q_{r}+\right. \\
& \left.\quad r_{r} \cdot Q_{r}\right] f\left(x_{r} \mid y, y \geq 0\right) d x_{r} \cdot \int_{0}^{\infty} g(y) d y- \\
& \sigma r k_{r} \cdot\left[\left(p_{r}-c\right)(\theta+\lambda)\left[\int_{-\infty}^{0} g(y) d y+w \int_{0}^{\infty} g(y) d y\right]\right\}
\end{aligned}
$$

(2) Expected Utility of Manufacturer under Independent Decision-making

$$
\begin{aligned}
U_{L}\left(E_{m L}\right) \\
=\int_{0}^{\infty}\left[\left(c-t+h_{y}\right) Q_{r} \cdot g(y) d y+\right. \\
\quad \int_{-\infty}^{0} w(c-t) Q_{r} \cdot g(y) d y-\sigma \cdot r k_{i} \cdot \\
\quad\left[\left(p_{i}-t\right)(\theta+\lambda)+(c-t)(1-\theta)\right] \int_{-\infty}^{0} g(y) d y
\end{aligned}
$$

(3) Expected Utility of Supply Chain

$$
\begin{aligned}
E_{n L}= & U_{L}\left(E_{r L}\right)+U_{L}\left(E_{m L}\right)-\int_{0}^{\infty}\left(c-t+h_{y}\right) Q_{r} g(y) d y- \\
& \int_{-\infty}^{0} w(c-t) Q_{r} g(y) d y
\end{aligned}
$$

\section{SIMULATION ANALYSES}

Assume that in a system composed of a manufacturer and several homogeneous retail stores, expected market demand is $a$; Expectation of probability density function of overlapping in lead time which obeys normal distribution is $\mu$, standard deviation is $\delta$; Wholesale price offered by manufacturer is $c$; Unit shortage cost of retail channel is $r_{r}$; Unit shortage cost of online channel is $r_{i}$; Unit production cost of manufacturer is $t$; Inventory holding cost of unit of product per unit time is $h$; Standard deviation of market demand is $\varepsilon$; The proportion of existing market demand for online channel is $\theta$; Proportion of new increased demand for online channel is $\lambda$; Substitution utility is $b$; Promotional services cost offered by retailer is $k$; The ratio manufacturer undertakes promotional service is $f$; Impact factor which is that the impact of lead time overlap on expected profit of two channels is $w$; Unit salvage of online channel is $s_{i}$; Unit salvage of retail channel is $S_{r}$. The coefficient of varia-

tion: $C V=\frac{\delta}{\mu} \times 100 \%$. Under risk-aversion attitude, data is chosen when $\mu=2, \delta=2 ; r k=0.5$ denotes risk-neutral attitude and $r k=0.2$ for risk-aversion attitude. All the parameters and their values are shown in Table $\mathbf{1}$.

6.1. Model Simulation Under General Risk Considering Risk-Aversion Attitude

\subsubsection{Independent Decision-Making Mode}


In this section, we can get the comparison results when manufacturers and retailers are taking independent decision in risk-aversion case. Retail price $p_{r}$ and online price $p_{i}$ will increase with the enhancement of substitution utility $b$. Specifically, the growth of $p_{r}$ is higher than that of $p_{i}$, that is because substitution utility is enhanced, customers tend to divert to online channel. Therefore, retailer tends to increase the price in order to reduce the loss caused by the loss of demand, while manufacturer will increase the price based on increase of demand so as to maximize expected profit.

\subsubsection{Collaborative Decision-Making Mode}

In this section, we attempt to analyze get the comparison results when supply chain members are taking collaborative decision in risk-aversion case. Based on collaboration mechanism among manufacturer and retailer, two channels determine the optimal pricing so as to maximize the respective profit. We are able to obtain simulation results, shown in Fig. (1).

From Fig. (1), we can see that online price $p_{i}$ and retail price $p_{r}$ will change with substitution utility $b$ and impact factor $w$. When $w$ remains unchanged, $p_{i}$ increases with the increase of $b$ while $p_{r}$ will decrease with the increase of $w$ and $b$ followed by intersection, which means with the increase of online customers, part of demand will divert to 
Table 1. Parameters of models.

\begin{tabular}{|c|c|c|c|c|c|c|c|c|c|c|c|c|c|c|c|c|}
\hline$\mu$ & $\delta$ & $c$ & $r_{r}$ & $r_{i}$ & $t$ & $h$ & $s_{i}$ & $S_{r}$ & $a$ & $\varepsilon$ & $\theta$ & $\lambda$ & $b$ & $k$ & $f$ & $w$ \\
\hline 0 & 0 & 35 & $0.3 \mathrm{t}$ & $0.3 \mathrm{t}$ & 25 & $0.001 \mathrm{t}$ & $0.25 \mathrm{t}$ & $0.25 \mathrm{t}$ & 100 & 25 & 0.1 & 0.1 & 0.1 & 10 & 0.1 & 0.1 \\
\hline 1 & 1 & 45 & $0.5 \mathrm{t}$ & $0.5 \mathrm{t}$ & 50 & -- & $0.5 \mathrm{t}$ & $0.5 \mathrm{t}$ & 200 & 50 & 0.2 & 0.2 & 0.2 & -- & 0.2 & 0.2 \\
\hline 2 & 2 & 55 & $0.7 \mathrm{t}$ & $0.7 \mathrm{t}$ & 75 & -- & $0.75 \mathrm{t}$ & $0.75 t$ & 300 & 75 & 0.3 & 0.3 & 0.3 & -- & 0.3 & 0.3 \\
\hline 3 & 3 & 65 & -- & -- & -- & -- & -- & -- & 400 & 100 & 0.4 & 0.4 & 0.4 & -- & 0.4 & 0.4 \\
\hline 4 & 4 & 75 & -- & -- & -- & -- & -- & -- & -- & -- & 0.5 & 0.5 & 0.5 & -- & 0.5 & 0.5 \\
\hline 5 & 5 & -- & -- & -- & -- & -- & -- & -- & -- & -- & 0.6 & 0.6 & 0.6 & -- & 0.6 & 0.6 \\
\hline 6 & 6 & -- & -- & -- & -- & -- & -- & -- & -- & -- & 0.7 & 0.7 & 0.7 & -- & 0.7 & 0.7 \\
\hline 7 & 7 & -- & -- & -- & -- & -- & -- & -- & -- & -- & 0.8 & 0.8 & 0.8 & -- & 0.8 & 0.8 \\
\hline-- & -- & -- & -- & -- & -- & -- & -- & -- & -- & -- & 0.9 & 0.9 & 0.9 & -- & 0.9 & 0.9 \\
\hline-- & -- & -- & -- & -- & -- & -- & -- & -- & -- & -- & 1 & 1 & 1 & -- & 1 & 1 \\
\hline
\end{tabular}



Fig. (1). $p_{i}$ and $p_{r}$ change with $w$ and $b$.

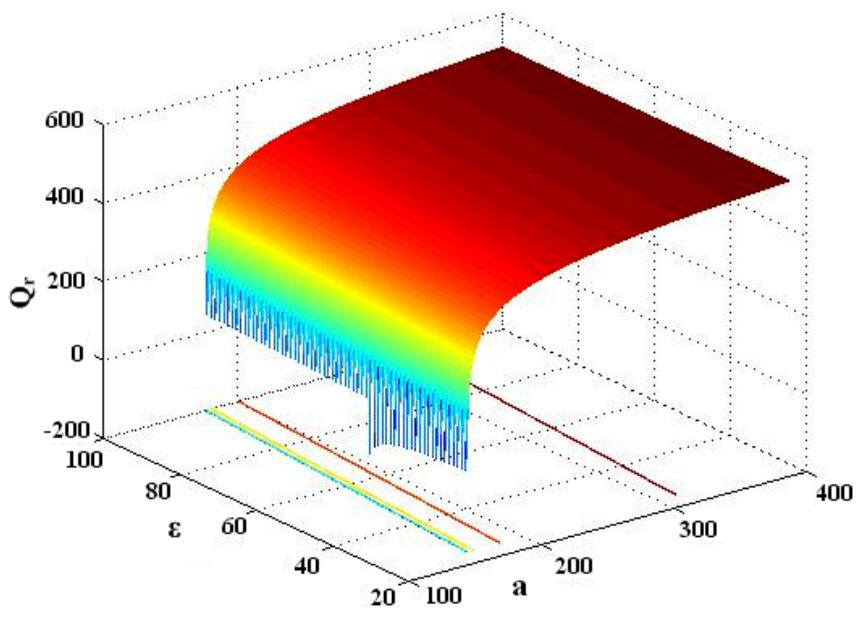

Fig. (2). $Q_{r}$ changes a and $\varepsilon$.

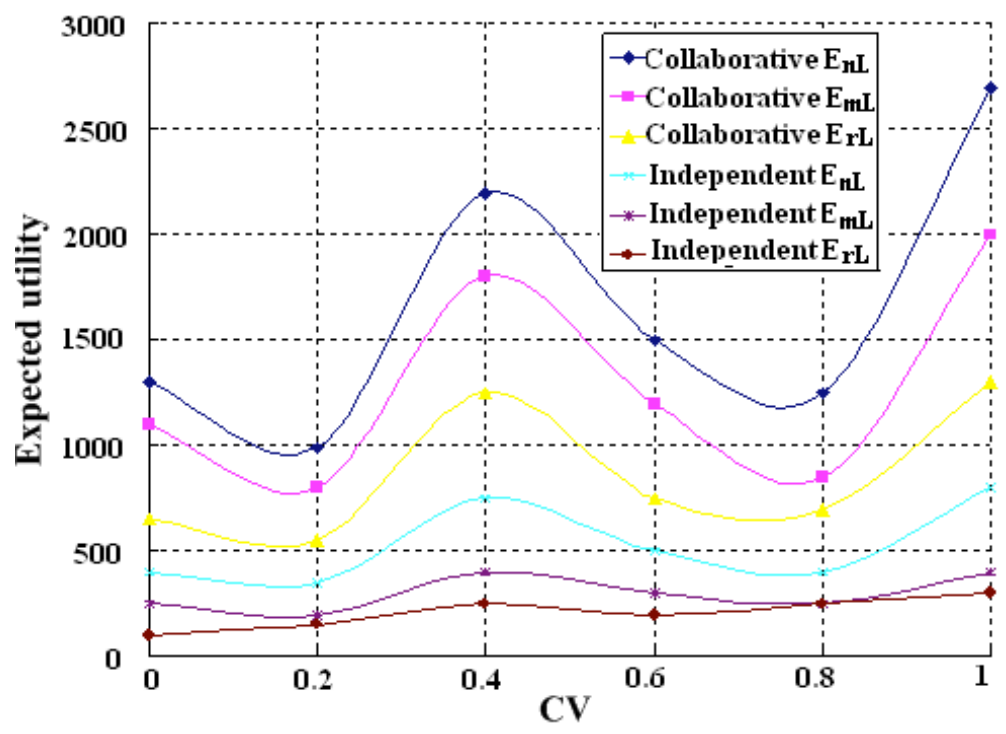

Fig. (3). The comparison of expected utility of retailer, manufacturer and supply chain under different CV. 


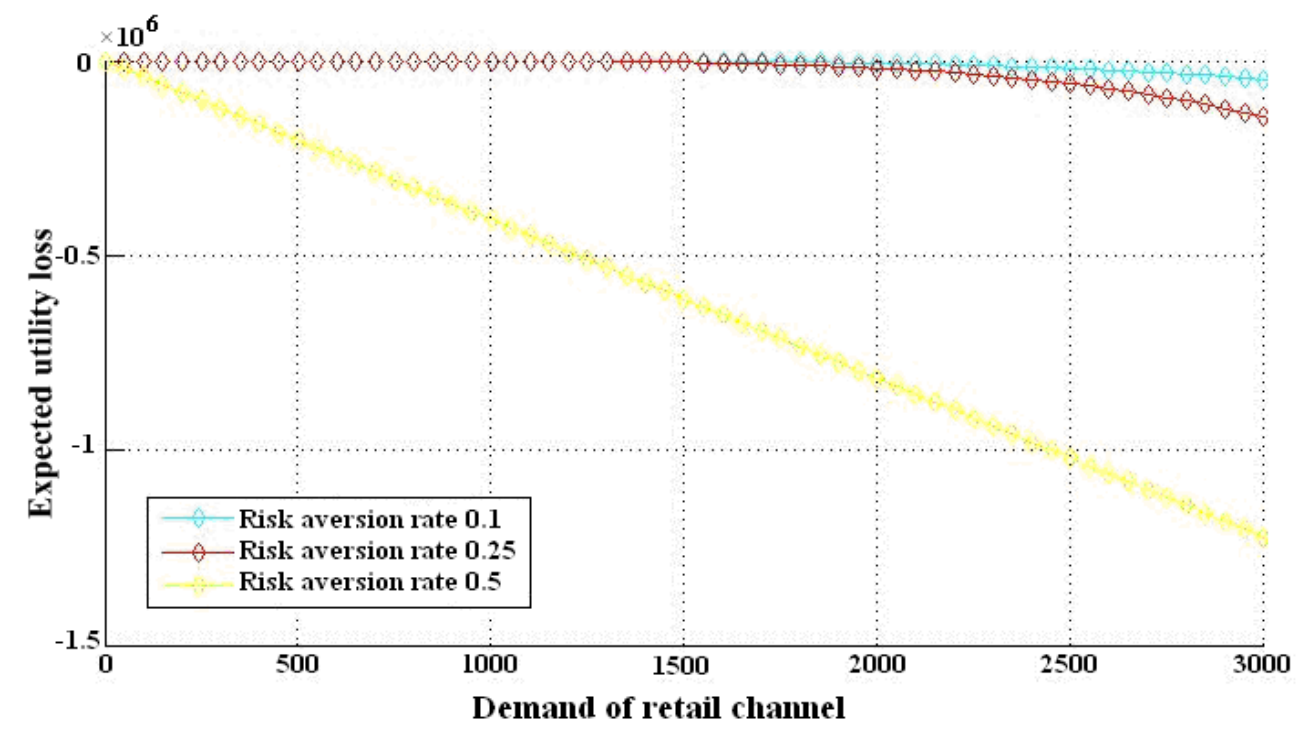

Fig. (4). The impact of demand of retail channel on expected utility of retail channel under independent decision in supply interruption situation.

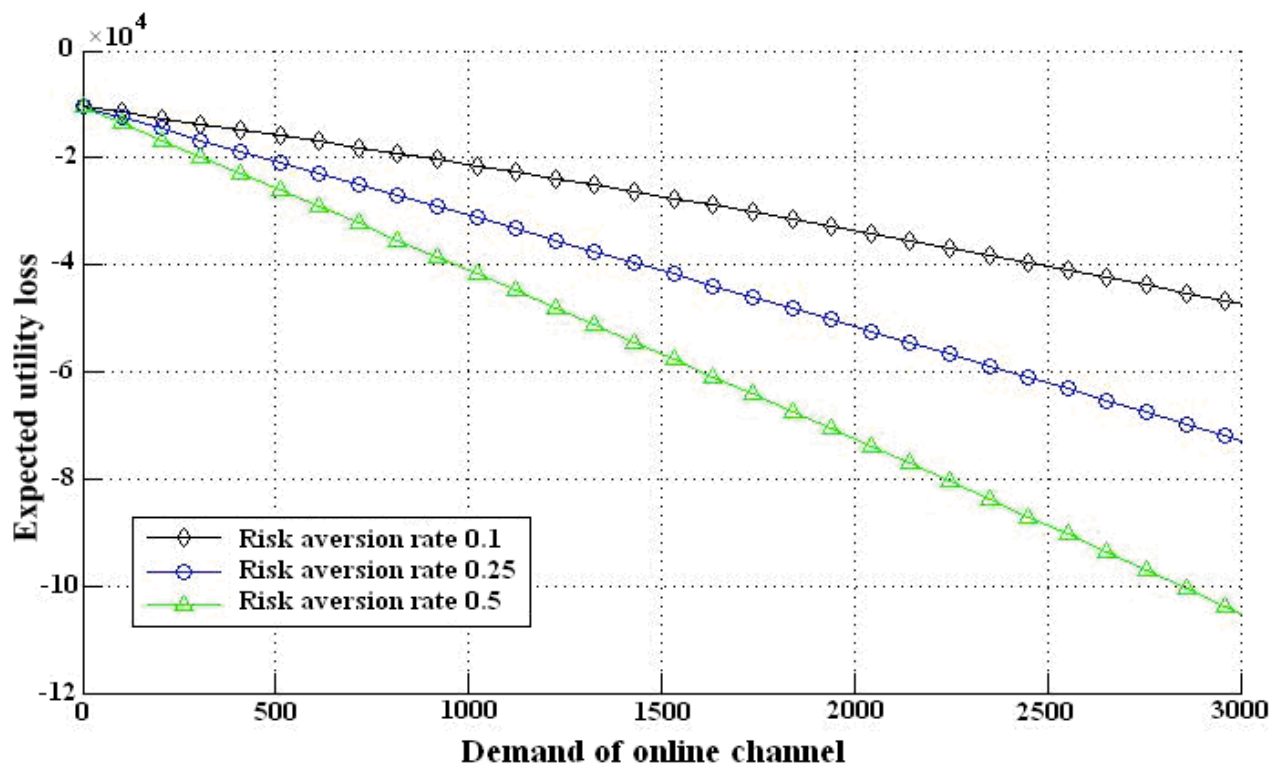

Fig. (5). The impact of demand of online channel on expected utility of online channel under independent decision in supply interruption situation.

online channel and retailer tends to raise sales price to increase revenue. Similarly, when $w$ and $b$ show a downward trend, $p_{r}$ will gradually increase.

Apart from the above analysis, from Fig. (2), collaborative decision-making among supply chain members is implemented, retail order quantity $Q_{r}$ changes with market size $\alpha$ and demand fluctuation coefficient. If $\varepsilon$ remains unchanged, retail order quantity $Q_{r}$ will increase with the increase of $\alpha$; meantime, if $\alpha$ remains unchanged, retail order quantity $Q_{r}$ will increase with the increase of $\varepsilon$ so as to reduce the risk of fluctuations caused by stock-out risk.

\subsubsection{Expected Utility with Risk-Aversion Attitude}

Expected utility of retailer and manufacturer under independent decision-making mode is lower than that of collaborative decision-making mode, which explains collaborative pricing strategy helps to balance allocation of risks and reduce costs and finally increase revenue, which is shown in (Fig. 3).

6.2. Model Simulation Under Interruption Risk Considering Risk-Aversion Attitude

6.2.1. The Impact of Demand on Expected Utility Loss Considering the Risk-Aversion Attitude

(1) Supply Interruption Risk

From Figs. (4 and 5), in supply interruption case, the situation of retailer is more complex than that of manufac- 


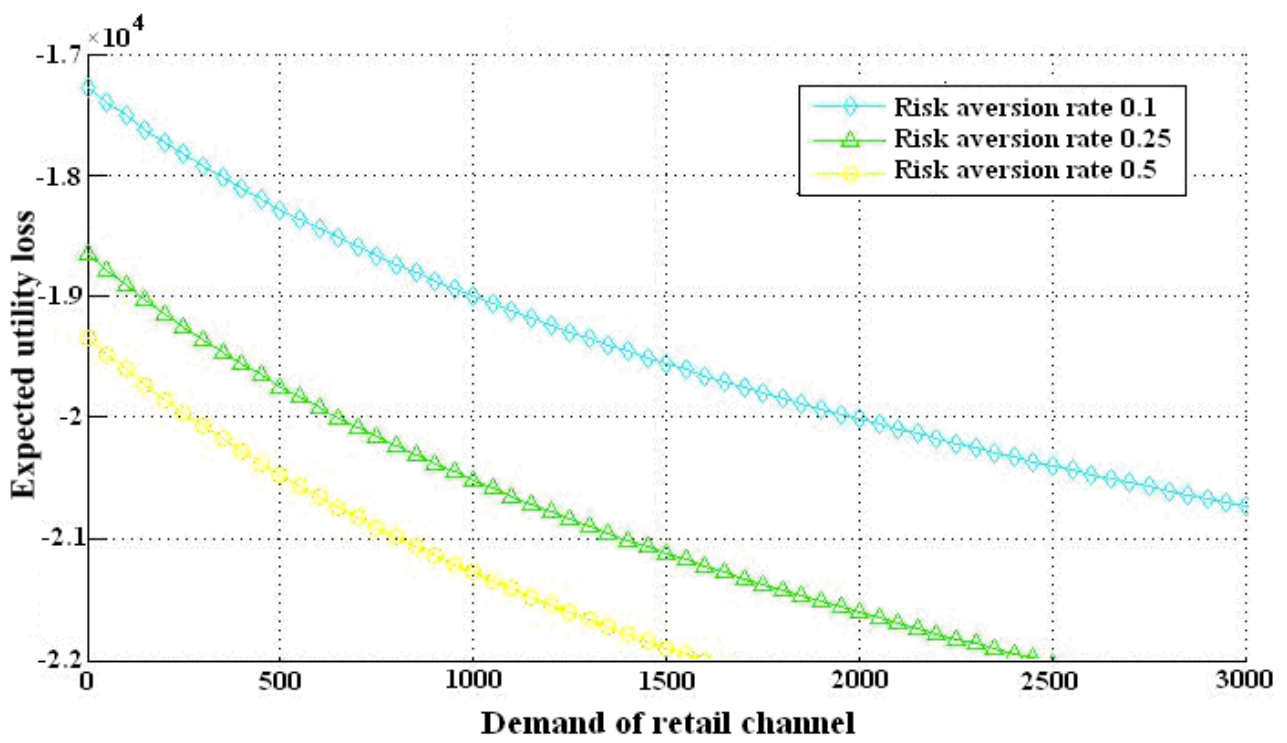

Fig. (6). The impact of demand of retail channel on expected utility of retail channel under independent decision in demand interruption situation.

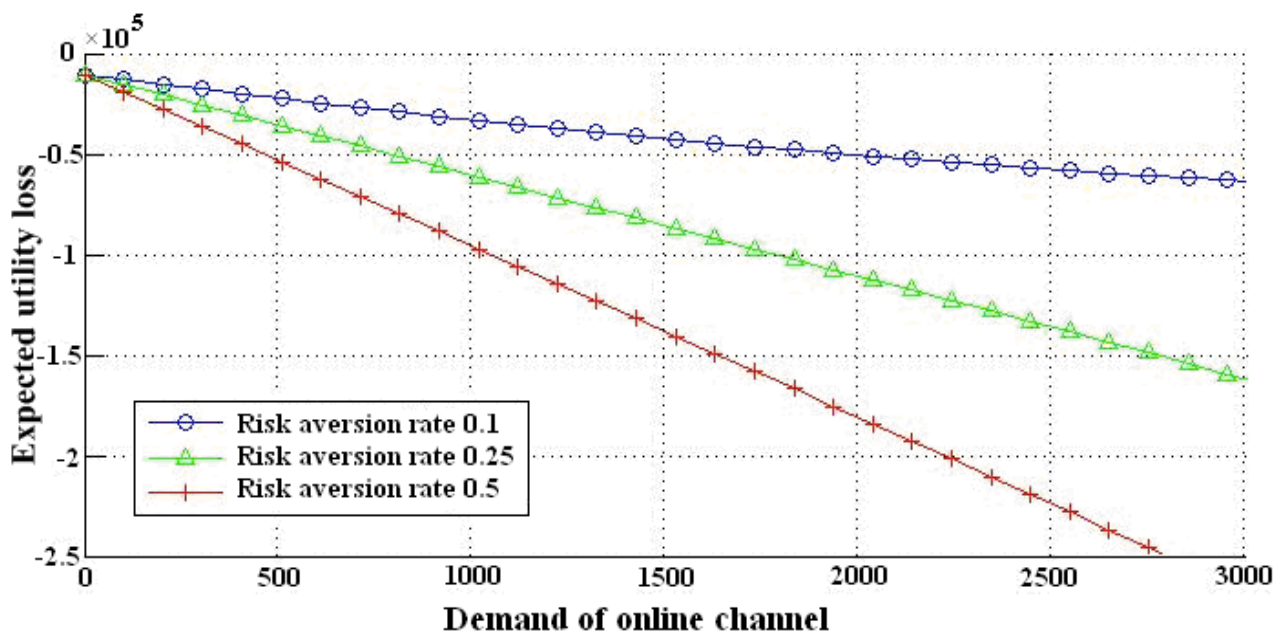

Fig. (7). The impact of demand of online channel on expected utility of online channel under independent decision in demand interruption situation.

turer, which is because expected utility of manufacturer was positively correlated with risk aversion rate.

\section{(2) Demand Interruption Risk}

From Figs. (6 and 7), we see the expected utility of retail channel and online channel tend to increase with the increase of market demand, where retailer's expected utility loss curve is a smooth concave curve, illustrating that the decreasing trend of expected utility loss of retail channel tend to be more intense with demand is growing. While manufacturer's expected utility loss curve tend to be convex when the rate of risk aversion is greater, which illustrate that the greater the rate of risk aversion, the greater the impact of expected utility loss.

\subsubsection{The Comparison of Expected Utility of Supply Chain under Different Risk Attitudes}

From Fig. (8), risk-aversion collaborative decisionmaking is better than risk-aversion independent decisionmaking mode; while risk-neutral independent decisionmaking mode is superior to risk-neutral collaborative deci- sion-making, which illustrate collaborative decision-making helps to obtain higher expected utility. Besides, the degree of impact of promotional cost on expected utility tend to decrease with the increase of promotional cost, showing that promotional cost is not the absolute factor to promote expected utility of supply chain. Meanwhile, expected utility curve based on risk-neutral independent mode is higher than expected utility curve based on risk-neutral collaborative mode, which means risk factor is prior to decision factor.

From Fig. (9), we can see the impact of risk factor plays more decisive role than the type of decision-making, where average unit salvage is linearly correlated with expected utility of supply chain, the greater of average unit salvage, the higher of expected utility of supply chain.

\section{CONCLUSION}

According to the above analysis, four observations are noteworthy. 


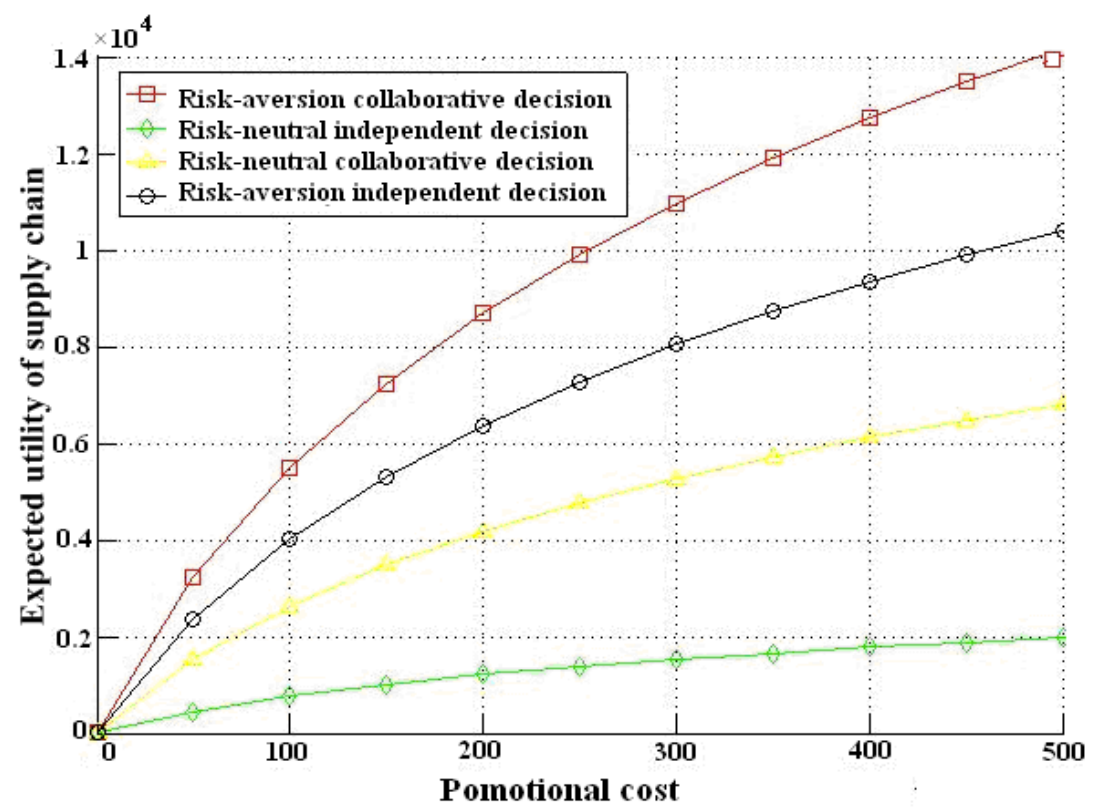

Fig. (8). The impact of promotional cost on expected utility of supply chain based on different decision mode under different risk attitudes.

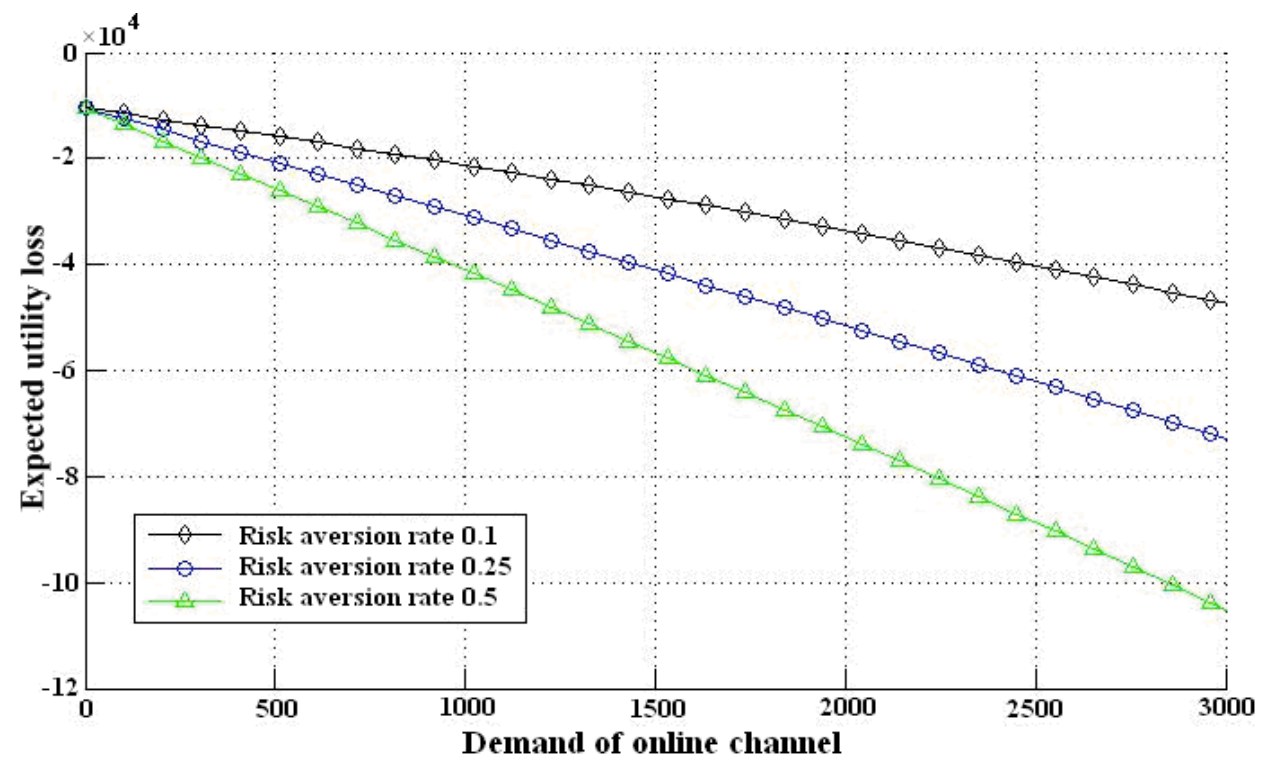

Fig. (9). The impact of average unit salvage on expected utility of supply chain based on different decision mode under different risk attitudes.

(1) In risk-aversion case, when both channels adopt independent pricing strategy, both channel concentrates on maximizing their own interest. When substitution effect is enhanced, retail channel as well as online channel will raise respective sales price, more specifically, the increase of retail price is higher than that of online price, so as to reduce the losses caused by the loss of retail channels demand.

(2) By comparison of expected profit of both channel as well as the total supply chain under risk-neutral and riskaversion, we can see that no matter which attitude they takes, the implantation of collaborative pricing strategy enables to help increase the profits.

(3) Moreover, the profit of respective channel under riskneutral environment is slightly higher than that under riskaversion environment, which is because risk-aversion partner loses a certain amount of opportunities when avoiding risks.
Specifically, both channels are better to take collaborative strategy if it is risk-aversion attitude.

(4) When faced with risk interruption, different attitudes towards risk have different impact. The more aggressive party may generate deadly effects; therefore it is necessary to consider helping channels to consider how to deal with risk interruption so as to enhance the adaptation of supply chain.

\section{CONFLICT OF INTEREST}

The authors confirm that this article content has no conflict of interest.

\section{ACKNOWLEDGEMENTS}

The authors thank the editor, associate editor as well as anonymous reviewers for their constructive suggestions. This work is partially sponsored by the National Natural 
Science Foundation of China (71172174, 70772073), Ph.D. Programs Foundation of Ministry of Education of China (20110075110003), Shanghai Pujiang Program (12PJC020), and Shanghai University Youth Teacher Training Program (ZZGCD15014).

\section{REFERENCES}

[1] J. Xiao, B. Dan, and X. Zhang, "Study on cooperation strategy between electronic channels and retailers in dual-channel supply chain," Journal of Systems Engineering, vol. 24, no. 6, pp. 673679, 2009.

[2] S. Li, Z. Zhang, and Y. Huang, "Effects of risk aversion on operational mode in dual-channel supply chain," Industrial Engineering and Management, vol. 16, no. 1, pp. 32-36, 2011.

[3] T. Chernonog, and T. Avinadav, "Profit criteria involving risk in price setting of virtual products," European Journal of Operational Research, vol. 236, no. 1, pp. 351-360, 2013.

[4] H. Wang, and J. Zhou, "Effect of competition and risk aversion on dual channel supply chain," Journal of Management, vol. 23, no. 1, pp. 10-17, 2010
[5] E. Huang, and M. Goetschalckx, "Strategic robust supply chain design based on the Pareto-optimal tradeoff between efficiency and risk," European Journal of Operational Research, vol. 237, no. 2, pp. 508-518, 2014.

[6] S.H. Yoo, "Product quality and return policy in a supply chain under risk aversion of a supplier," International Journal of Production Economics, vol. 154, pp. 146-155, 2014.

[7] S. Chen, H.W. Wang, Y. Xie, and C. Qi, "Mean-risk analysis of radio frequency identification technology in supply chain with inventory misplacement: risk-sharing and coordination," OMEGAInternational Journal of Management Science, vol. 46, pp. 86-103, 2013.

[8] Q.H. Zhang, M. Dong, J.W. Luo, and A. Segerstedt, "Supply chain coordination with trade credit and quantity discount incorporating default risk," International Journal of Production Economics, vol. 153, pp. 352-360, 2014.

[9] L. Zhu, K.S. Hong, and C. Lee, "Optimal ordering policy of a riskaverse retailer subject to inventory inaccuracy," Mathematical Problems in Engineering, vol. 2013, pp. 1-9, 2013.

(C) Liu and $\mathrm{Xu}$; Licensee Bentham Open.

This is an open access article licensed under the terms of the Creative Commons Attribution Non-Commercial License (http://creativecommons.org/licenses/by-nc/3.0/) which permits unrestricted, non-commercial use, distribution and reproduction in any medium, provided the work is properly cited. 